\title{
Mediterranean diet and cancer: epidemiological evidence and mechanism of selected aspects
}

\author{
Giuseppe Grosso ${ }^{1}$, Silvio Buscemi ${ }^{2}$, Fabio Galvano ${ }^{1}$, Antonio Mistretta ${ }^{3}$, Stefano Marventano ${ }^{3}$, Vanessa La Vela ${ }^{4}$, \\ Filippo Drago ${ }^{5}$, Santi Gangi ${ }^{6}$, Francesco Basile ${ }^{6}$, Antonio Biondi ${ }^{*}$
}

From 26th National Congress of the Italian Society of Geriatric Surgery

Naples, Italy. 19-22 June 2013

\begin{abstract}
Background: Populations living in the area of the Mediterranean Sea suffered by decreased incidence of cancer compared with those living in the regions of northern Europe and US countries, attributed to healthier dietary habits. Nowadays, we are assisting to a moving away from the traditional Mediterranean dietary pattern, but whether this changing is influencing risk of cancers is still unclear. The aim of the study was to review recent evidence on potential relationship between the adherence to the Mediterranean diet and cancer.

Discussion: The most recent pooled analyses of epidemiological studies supported strongly the hypothesis that the Mediterranean diet may play a role in preventing several types of cancers, especially those of digestive tract, whereas contrasting results were reported for hormone-dependent cancers. Specific aspects of the Mediterranean diet such as high fruit and vegetables and low red processed meat intake may explain such protective effects. Moreover, evidence regarding olive oil and whole grains increase the beneficial effects of such dietary pattern against cancer.
\end{abstract}

Conclusions: Literature evidence actually demonstrates that the increased adherence to the Mediterranean dietary pattern is beneficial to health across populations and may translate a protective effect with certain cancers.

\section{Background}

Nowadays, the advent of improved screening programs and surgical therapeutic approaches have positively affected survival from many cancers [1-3]. On the other hand, differences according non-modifiable and modifiable factors may affect both stage at diagnosis, comorbidity status, and survival $[4,5]$. Despite the global cancer burden, only few cancers are genetically determined and the most of cancer genesis and promotion mechanisms depends on environmental factors [6-10]. It has been estimated that many of the cancers occurring today are preventable by applying preventive interventions derived by knowledge that we already have [11]. The selective geographical localization of higher incidence rates of many types of cancers in Western countries is attributable to factors related to

\footnotetext{
* Correspondence: abiondi@unict.it

${ }^{6}$ Department of General Surgery, Section of General Surgery and Oncology, University Medical School of Catania, Italy

Full list of author information is available at the end of the article
}

voluntary behaviors such as nutrition and physical activity habits [12]. Historically, populations living in the area of the Mediterranean Sea suffered by decreased incidence of cancer compared with those living in the regions of northern Europe and US countries [13]. This singular condition has been attributed to the traditional dietary pattern commonly used by populations living in this area, which has been recognized to protect also from cardiovascular diseases [14]. The Mediterranean diet consists of: (i) fruits, cooked vegetables and legumes, wholegrain and unrefined cereals, (ii) olive oil as primary source of dietary lipids, (iii) nuts, (iv) a moderate intake of wine, especially during meals with fish and seafood, dairy products and eggs finally (v) a low consumption of red meat and sweets. Despite a general definition of the Mediterranean diet may be given, there is no univocal pattern, since a variation among countries exist. The studies conducted to estimate the effects on health of the Mediterranean diet aimed to consider the diet preferably as a whole nutrition pattern 
rather than referring to the single components of the diet, enhancing the role of interactions between the multiple components of the diet. Nowadays, we are assisting to a moving away from the traditional dietary pattern in these regions, generating several variations of the original pattern, or even a "Westernization" of the diet due to the modernization of the urban areas and a globalization of the lifestyle, including diet. Despite a decrease in the adherence to the Mediterranean diet in Mediterranean countries during the last decades has been observed [15], whether this changing in dietary and lifestyle patterns are influencing risk of cancers is still unclear. Studying cancer causes is challenging because increased risk of disease does not only depend on factors related to diet, rather to lifestyle and cultural models of a population. Moreover, due to the long latent period for a malignancy to develop, identify the specific associations between such factors and cancer over a lifetime is difficult. However, accurate literature reviews may help to point-out hypotheses on potential relationship between lifestyle factors such as dietary habits, and cancer. Evidence from epidemiological studies may provide support to public health recommendations and policies.

\section{Evidence from epidemiological studies}

In the past decades, evidence on the health effects of the Mediterranean diet has been reported in many different cohort studies by suggesting its possible protective role against neoplastic diseases. A recent meta-analysis of prospective cohort studies by Sofi et al. [16] concluded that the Mediterranean diet is responsible of a $6 \%$ reduction from death and/or the incidence of neoplastic diseases (cancer incidence or mortality RR 0.94; 95\% CI: 0.92, 0.96). Updated reports from a large cohort such as the European Prospective Investigation Into Cancer and nutrition including 335,873 individuals have found a lower overall cancer risk among those with greater adherence to Mediterranean diet (HR 0.96, 95\% CI $0.95,0.98$ ) for a two-point increment of the Mediterranean diet score [17]. The apparent inverse association was stronger for smoking-related cancers than for cancers not known to be related to tobacco. In all, $4.7 \%$ of cancers among men and $2.4 \%$ in women would be avoided in this population if study subjects had a greater adherence to Mediterranean dietary pattern. However, no data was given for specific cancer risk.

More recent epidemiological studies focused on association between the Mediterranean diet and incidence of specific malignancies, the most of them regarding colorectal and breast cancers. Regarding colorectal cancer, an a study conducted on 45,275 participants of the Italian section of the EPIC study followed for a mean of 11.28 years, the Italian Mediterranean Index was inversely associated with cancer risk (HR 0.50, 95\% CI: 0.35, 0.71 for the highest category compared to the lowest, P-trend: 0.043). Results did not differ by sex. Highest Italian Mediterranean Index score was also significantly associated with reduced risks of any colon cancer (HR 0.54, 95\% CI: 0.36, 0.81), distal colon cancer (HR 0.44, 95\% CI: 0.26, 0.75) and rectal cancer (HR $0.41,95 \%$ CI: $0.20,0.81$ ), but not of proximal colon cancer [18]. In the large cohort of 492,382 subjects belonging to the National Institutes of Health-AARP Diet and Health Study that the MD decreased colorectal cancer risk in males (RR 0.72, 95\% CI: 0.63, 0.83) was observed, whereas no association in females was reported [19]. Similar results were found in another study conducted on 32,415 subjects included in the contest of the Prostate, Lung, Colorectal, and Ovarian (PLCO) Cancer Screening Trial which assessed that the Mediterranean dietary pattern was associated with reduced risk of colorectal adenoma, especially in men (overall colorectal adenoma OR $0.79,95 \%$ CI: $0.68,0.92$ ) [20]. On the contrary, a study conducted on a total of 87,256 women and 45,490 men followed for $\leq 26$ years found no association with adherence to the Mediterranean Cancer and protection from colorectal cancer [21].

An investigation conducted among the women included in the EPIC cohort showed that adherence to a Mediterranean diet excluding alcohol was related to a modest reduced risk of breast cancer in postmenopausal women, and this association was stronger in receptornegative tumors [22]. Similar findings have been reported in 33,731 women from the UK Women's Cohort Study with a non-significant inverse association with increasing adherence to the Mediterranean diet pattern in premenopausal but not postmenopausal women [23] whereas a marginally significant inverse association (HR 0.78 for every 2 points, $95 \%$ CI: $0.62,0.98$ ) among postmenopausal women in the Greek arm of the EPIC study was found [24]. Moreover, although the Minnesota Breast Cancer Family Study did not find an association between MD and breast density, a stratified analysis identified a protective role of the Mediterranean diet among current smokers (beta $=-1.68, \mathrm{P}=0.002$ ) but not among nonsmokers (beta $=-0.08, \mathrm{P}=0.72 ; \mathrm{P}$ for interaction $=0.008$ ) [25]. The study of the histological features of the breast cancer observed leaded to contrasting results. Fung et al. observed no association between the diet quality indices and total or positive estrogen receptor $(\mathrm{ER}+)$ breast cancer risk with postmenopausal women who scored high in $\mathrm{MD}$ adherence score had a lower risk of negative estrogen receptor (ER-) breast cancer (OR 0.79 95\% CI: 0.601.03) [26]. Contrarily, a French study reported an increase of breast cancer risk with the Western diet for $\mathrm{ER}+$ /positive progesterone receptor $(\mathrm{PR}+)$ tumors (HR 1.20, 95\% CI: 1.03-1.38), and a negative association of the MD for breast cancer risk (HR 0.85, 95\% CI: 0.75-0.95), especially for ER+/PR- tumors [27]. 
Among the other cancer incidences explored within large epidemiological prospective cohort studies, some investigation regarded prostate, gastric, and endometrial cancers. A study aimed to explore the association between adherence to a relative Mediterranean diet and incident gastric adenocarcinoma within the EPIC cohort reported that a 1-unit increase in the Mediterranean diet score was associated with a decreased risk of cancer of 5\% (95\% CI: 0.91, 0.99) [28]. No significant association was also observed between a Mediterranean diet and total prostate cancer or between any of the indices and advanced or fatal prostate cancer in a cohort of 293,464 US men in the National Institutes of Health (NIH)-AARP Diet and Health Study [29]. In individual component analyses, the fish and $\omega-3$ fatty acids were inversely associated with fatal prostate cancer $(\mathrm{HR}=$ 0.79, 95\% CI: $0.65,0.96$, and HR $=0.94,95 \%$ CI: 0.90 , 0.98 , respectively). Regarding the incidence of endometrial cancer, a study conducted in San Francisco on woman aged 35-79 showed that a greater consumption of the Western diet was associated with a $60 \%$ increase in the risk cancer but no association with endometrial cancer was found with the Mediterranean diet [30].

The association between the Mediterranean diet and cancer has been studied in a series of case-control studies conducted on breast, colon, and upper aero-digestive tract cancers [31-33]. The one of Demetriou et al. [31] did not report any association between breast cancer and Mediterranean diet, although higher consumptions of vegetables, fish and olive oil, were independently associated with decreased risk of disease. Contrarily, a study including two case-control groups of Hispanic (757 cases, 867 controls) and non-Hispanic white women (1524 cases, 1598 controls) from the Four-Corners Breast Cancer Study reported that the Mediterranean dietary patterns were associated with lower risk of breast cancer (OR 0.76, 95\% CI: 0.63, 0.92) [34]. Another series of studies focused on the mediating effect of Mediterranean diet on a variety of lifestyle behaviors and colorectal cancer, have found that increase in the adherence to the Mediterranean diet was associated with lower likelihood of colorectal cancer whereas a positive association with alcohol intake and smoking habit was reported [32,33]. Finally, the study conducted in the context of the European alcohol-related cancers and genetic susceptibility in Europe project, reported that stricter adherence to the Mediterranean diet was associated with a substantial and significant decrease in UADT cancer risk (30 \% for a two-unit increase in score) [35], confirming results of a work reporting data from three case-control studies conducted in Italy between 1992 and 2000 in which an OR of 0.40 for oral and pharyngeal, 0.26 for esophageal, and 0.23 for laryngeal cancer in subjects more adherent to the Mediterranean dietary pattern was found [36].

\section{Selected components of Mediterranean diet protecting against cancer \\ Fruit and vegetables}

The role of the main components of the Mediterranean diet in several common epithelial cancers, including digestive and selected non-digestive tract neoplasms, have been showed in a report of La Vecchia [37] reviewing a series of case-control studies conducted in Italy between 1983 and 1998 over 12,000 cases of 20 cancer sites and 10,000 controls. The relative risk (RR) for most epithelial, digestive tract, breast, female genital tract, urinary tract cancers was decreased with increasing vegetable and fruit consumption, probably due to the beneficial effects of a number of antioxidants and other micronutrients which showed themself an inverse relationship with cancer risk [38].

Raw and fresh vegetables, leafy green vegetables, cruciferous vegetables, carrots, broccoli, cabbage, lettuce, and raw and fresh fruit (including citrus fruit and tomatoes) appear to be protective against cancer due to their high content of antioxidants compounds, such as carotenoids, vitamin $C$, vitamin $E$, selenium, dietary fiber (and its components), dithiolthiones, glucosinolates (isothiocyanates and indoles), polyphenols, protease inhibitors, allium compounds, plant sterols, and limonene [39,40]. A high intake of glucosinolate-containing cruciferous vegetables, such as Brussels sprouts (Brassica oleraceae), has been linked to a decreased cancer risk [41]. Indoles and isothiocyanates, two major groups of glucosinolate breakdown products, attenuate the effects of polycyclic aromatic hydrocarbons (PAHs) and nitrosamines under experimental conditions [42]. In addition, indole-3-carbinol (I3C), a naturally occurring component of Brassica vegetables, such as broccoli, cabbage, and Brussels sprouts, has been found to prevent the progression of different cancers and in particularly induces a G(1) cell-cycle arrest of human breast cancer cells. Moreover, indole-3-carbinol (I3C) has significant therapeutic potential for treatment of human cancers associated with high levels of elastase [43]. This antitumoral effect is expressed by a noncompetitive inhibition of elastase enzymatic activity. Indeed, high accumulation of cyclin E protein is associated with cancer cell proliferation, poor clinical outcomes, decreased response to chemotherapy, reduced response to endocrine treatment and a reduced survival rate in some human cancers [44].

Citrus fruit, especially blond and red oranges (Citrus sinensis), contains a high amount of antioxidant components including polyphenols, flavanones, anthocyanins, hydroxycinnamic acids, and ascorbic acid (depending on the variety of fruit) [45]. Laboratory studies have showed that citrus flavonoids and anthocyanins are able to inhibit the growth of several tumors, including breast and colorectal cancer $[46,47]$ through inhibiting multiple cancer-related biological pathways, such as carcinogen 
bio-activation, cell-signaling, cell cycle regulation, angiogenesis, and inflammation $[48,49]$. Citrus flavonoids have been hypothesized to inhibit the matrix metalloproteinase (MMP) secretion, migration, invasion and adhesion [50-52], and to have pro-apoptotic activity [53-56].

Tomatoes are undergoing particular attention because they clearly characterize the Mediterranean diet. Eating tomatoes has been associated with reduced risks of some types of cancer and other diseases [57]. Their constituents such as carotenoids and flavonoids contribute to the prevention of ultra violet ray damage in humans [58] and are efficient antioxidants capable of scavenging reactive oxygen species generated under conditions of photooxidative stress [59]. Lycopene, red pigment present in many red fruits and vegetables, is the major carotenoid of the tomato and is a very efficient singlet oxygen quencher in the group of carotenoids [58]. Tomatoes and related tomato products are the major source of lycopene compounds, and are also considered an important source of carotenoids in the human diet. Industrial and thermal processing (bleaching, retorting, and freezing processes) generally causes some loss of lycopene in tomato-based foods, although lycopene bioavailability in processed tomato products is higher than in unprocessed fresh tomatoes [60]. Food processing may improve lycopene bioavailability by breaking down cell walls, which weakens the bonding forces between lycopene and tissue matrix, thus making lycopene more accessible [61]. Supplementation of tomato products, containing lycopene, has been assessed to have similar effects on health than consuming tomato. Indeed, such products supplementation lower biomarkers of oxidative stress and carcinogenesis [62] and protect the skin against UVR-induced effects (i.e., erythema) $[63,64]$. Moreover, tomato extract has been shown to ameliorate tissue damage, to decrease the risk of many chronic diseases including several types of cancer (i.e., prostate cancer) $[65,66]$. Purple tomatoes, highly enriched with anthocyanins, have been shown to prolong life under experimental conditions suggesting that they have additional health-promoting effects [67].

\section{Fish vs. meat}

Frequent fish intake has been related to decreased risk of several neoplasms whereas red meat intake demonstrated detrimental effects, especially increasing the risk of colorectal cancer [68], through production of N-nitroso compounds and, when cooked at high temperatures, heterocyclic amines and polycyclic aromatic hydrocarbons (which are known carcinogens) [69]. Red meat and processed meat intake has been hypothesized to increase breast cancer risk but while both case-control and ecologic studies have supported a positive association, prospective cohort studies have been inconsistent [70].
Further investigations of potential effect modifiers, such as analyses by hormone receptor or menopausal status, may provide valuable insight to potential patterns of associations. Indeed, a meta-analysis including only studies conducted on premenopausal women demonstrated a pooled RR of 1.24 (95\% CI 1.08, 1.42) [71]. Among the more evident associations, meat and processed meat intake has been related with esophageal $[72,73]$, lung [74], pancreatic [75], bladder [76] cancers, whereas inconclusive results were reported for prostate [77], kidney [78], and ovarian [79] cancers.

\section{Whole-grain}

Consumption of refined and whole grains, in form of bread, pasta, and rice, is a major characteristic of MD and has been associated with reduced cancer risk, including those of the upper aero-digestive tract, stomach, colorectum, liver, breast, ovary, bladder and kidney [80], while refined grain intake was associated with an increased risk of stomach, colorectal, upper aero-digestive tract and thyroid cancers [81]. The beneficial role of whole-grain has been hypothesized to be due to their high content of fibres, which OR of colon and rectal cancers were below unity for high intakes of most types of dietary fibres, especially those contained in rice [82], whereas no appreciable differences emerged between the two sites [83-85]. Nevertheless, high intakes of most types of dietary fibres have been associated with lower odds also for upper aero-digestive tract neoplasms $[86,87]$. Dietary fibers may act on cancer risk by improving faecal bulking and satiety, viscosity and short chain fatty acid production, enhancing fermentation of metabolites. Fibres may protect from colorectal cancer by increasing stool bulk, thus reducing transit time and contact of carcinogens with the colonic mucosa or by acting as probiotic, namely a nondigestible food ingredient whose beneficial effects on the host result from the selective stimulation of growth and/or activity of members of the bacterial community that inhabits the human bowel [88]. The fermentation of dietary fibre by the microflora enhances the levels of effective metabolites which are potentially protective against colon cancer inhibiting cell growth and promoting apoptosis as well as differentiation $[89,90]$.

Another hypothesis investigated on the possible mechanism of cancer promotion related to refined and whole grain foods, was their connection with the dietary glycaemic index (GI) (an indicator of the rate of adsorption of carbohydrates and, hence, a measure of insulin demand) and glycaemic load (GL) (which combines the quality as well as the quantity of carbohydrate consumed). Both GI, and in particular GL, have been suggested to be relevant factors in the cancer incidence due to the potential role of insulin and insulin grow factor (IGF) in cancer 
promotion [91,92]. With reference to digestive tract cancers, there was a direct association of colon and gastric cancer with such indices; among female hormone-related neoplasms, direct associations with breast, ovarian and endometrial cancers; among upper aero-digestive tract neoplasms, an association was found for those of the oral cavity/pharynx, esophagus and larynx; finally, a significant association was found for thyroid and prostate cancers [84]. Results of recent meta-analyses of prospective cohort studies reported a pooled RR for all diabetes-related cancers of 1.07 (95\% CI: 1.04, 1.11) for GI and 1.02 (95\% CI: $0.96,1.08)$, whereas the analysis of site-specific cancer risks revealed a significant associations for GI in relation to breast cancer (RR 1.06, 95\% CI: 1.02, 1.11) and colorectal cancer (RR 1.08, 95\% CI:1.00, 1.17) and for GL to endometrial cancer (RR 1.21, 95\% CI: 1.07, 1.37) [93] whereas no significant risk of digestive tract neoplasms was found [94]. The role of fibre in preventing chronic disease also depends on their numerous bioactive compounds with antioxidant and anti-carcinogenic properties, especially those in the bran and germ (minerals, trace elements, vitamins, carotenoids, polyphenols and alkylresorcinols), the properties of which have been described above. Wholegrain wheat is also a rich source of methyl donors and lipotropes (methionine, betaine, choline, inositol and folates) that may be involved in cardiovascular and hepatic protection, lipid metabolism and DNA methylation [95].

\section{Olive oil}

The association of olive oil and other mono- and unsaturated fats with many types of cancer has been reviewed, reporting a favorable effect on breast, ovarian, colorectal, but mostly of upper aero-digestive tract cancers [84]. A recent meta-analysis of 13800 patients and 23340 controls in 19 observational studies concluded that higher intake of olive oil intake was associated with lower odds of having any type of cancer $(\log$ OR -0.41 , 95\% CI: $-0.53,-0.29$ ), breast cancer (log OR $-0.45,95 \%$ CI: $-0.78,-0.12)$, and a cancer of the digestive system (log OR -0.36, 95\% CI: $-0.50,-0.21$ ), compared with the lowest intake [96]. Experimental and human cellular studies have provided new evidence on the potential protective effect of olive oil on certain cancers such as breast, colorectal and prostate cancers [97]. Olive oil has been suggested to inhibit colon cancer development by inducing apoptosis in large intestinal cancer cells and down-regulating the expression of cyclooxygenase 2 $(\mathrm{COX}-2)$ and $\mathrm{Bcl}-2$ proteins that have a crucial role in colorectal carcinogenesis [98]. Among its potentially health-promoting components, tyrosol and hydroxytyrosol have been demonstrated to decrease glutathione (GSH), the activation of the transcription factor Nuclear Factor $-\kappa \mathrm{B}$ and cell death which may be implicated in the carcinogenetic processes [99].

\section{Red wine}

Wine, especially red wine, is rich in several plant compounds with a wide range of health properties. Whether moderate intake of red wine may protect against cancer is still controversial [100]. Many of the beneficial properties of red wine depend on its content of resveratrol (3,4',5-trihydroxy-trans-stilbene), a phytoalexin found also in grape skins, peanuts and berries, that may act as an antioxidant and cancer chemopreventive agent thanks to its ability of inhibiting tumor initiation, promotion, and progression [101]. Indeed, several studies have shown that resveratrol and some of its analogs interfere with signal transduction pathways, modulate cell cycle-regulating proteins, and are a potent inducer of apoptosis in multiple carcinoma cell lines [102]. Recently, the chemopreventive properties of resveratrol have been associated with the inhibition of Nuclear Factor-kB activity [103]. In addition, resveratrol exhibits anti-inflammatory, growth-inhibiting activity and immunomodulation properties [104]. Interestingly, the aforementioned health benefits of resveratrol against cancer produced in the laboratory setting cannot be translated in effects on free-living population. Indeed, some cohort studies conducted on lung [105], colorectal [106], and prostate [107] cancers, reported that red wine does not contribute appreciably to the etiology or protection of such malignancies. It may be speculated that the beneficial effects of antioxidant compounds contained in red wine may be offset by the detrimental effects of alcohol.

\section{Conclusions}

Several aspects of the MD may lead to some health benefits that reflect a higher survival and a lower incidence of cancer. However, limitations of literature studies have to be considered. Firstly, studies exploring the adherence to the MD and cancer incidence or mortality, have a methodological limitation due to the longer follow-up period, during which the latency of dietary influences on the risk of death may be influenced by changes in dietary habits, if diet is assessed at enrolment and if a cumulative exposure to a more or less healthy diet is considered. Moreover, some further confounding factors such as, the effect of dietary supplements, may lead to sure bias if studies do not control or results are not adjusted for these variables. Finally, possible measurement error and recall bias should be taken in to account. Another limitation of some studies is the availability of information on nondietary variables such as socioeconomic and cultural status. In fact, the only variable taken in account was the latest educational achievement which is both objectively ascertainable and internationally applicable, but it is not comprehensive of other factors influencing the lifestyle. Another non-dietary factor that should be considered in these kinds of studies and is often missing or not 
homogeneously measured is the physical activity level. In fact physical activity is an independent risk factor for many types of cancer. Despite these limitations, literature evidence actually demonstrates that the increased adherence to the Mediterranean dietary pattern is beneficial to health across populations and may translate a protective effect with certain cancers.

\section{Competing interests}

The authors declare that they have no competing interests.

\section{Authors' contributions}

GG: conception and design, drafting the manuscript; AM, SM, VLV: drafting the manuscript; SB, FG, FD, FB, SG, AB: critical revision, given final approval of the version to be published.

\section{Acknowledgements}

Giuseppe Grosso was supported by the International Ph.D. Program in Neuropharmacology, University of Catania Medical School, Catania, Italy. The funders had no role in the study design, data collection and analysis, decision to publish, or preparation of the manuscript.

\section{Declarations}

Funding for this supplement has come from University funds.

This article has been published as part of BMC Surgery Volume 13 Supplement 2, 2013: Proceedings from the 26th National Congress of the Italian Society of Geriatric Surgery. The full contents of the supplement are available online at http://www.biomedcentral.com/bmcsurg/supplements/13/S2

\section{Authors' details}

'Department of Drug Sciences, Section of Biochemistry, University of Catania, Catania, Italy. ${ }^{2}$ Department of Internal Medicine, University of Palermo, Palermo, Italy. "Department "G. F. Ingrassia" Section of Hygiene and Public Health, University of Catania, Catania, Italy. ${ }^{4}$ Department of Eating Disorders Unit, Niguarda Hospital, University of Milan, Milan, Italy. ${ }^{5}$ Department of Clinical and Molecular Biomedicine, Section of Pharmacology and Biochemistry, University of Catania, Catania, Italy. ${ }^{6}$ Department of General Surgery, Section of General Surgery and Oncology, University Medical School of Catania, Italy.

Published: 8 October 2013

\section{References}

1. Biondi A, Grosso G, Mistretta A, Marventano S, Toscano C, Gruttadauria S, Basile F: Laparoscopic-assisted versus open surgery for colorectal cancer: short- and long-term outcomes comparison. Journal of laparoendoscopic \& advanced surgical techniques Part A 2013, 23(1):1-7.

2. Cantore F, Colombo EM, Giuseppe MD, Biondi A, Rausei S, Dionigi G, Rovera F, Boni L, Dionigi R: Single access cholecystectomy using standard laparoscopic instruments. Updates in surgery 2011, 63(1):31-34.

3. Biondi A, Tropea A, Basile F: Clinical rescue evaluation in laparoscopic surgery for hepatic metastases by colorectal cancer. Surgical laparoscopy, endoscopy \& percutaneous techniques 2010, 20(2):69-72

4. Vacante M, D'Agata V, Motta M, Malaguarnera G, Biondi A, Basile F, Malaguarnera M, Gagliano C, Drago F, Salamone S: Centenarians and supercentenarians: a black swan. Emerging social, medical and surgical problems. BMC surgery 2012, 12(Suppl 1):S36.

5. Grosso G, Biondi A, Marventano S, Mistretta A, Calabrese G, Basile F: Major postoperative complications and survival for colon cancer elderly patients. BMC surgery 2012, 12(Suppl 1):S20.

6. Ragusa M, Statello L, Maugeri M, Majorana A, Barbagallo D, Salito L, Sammito M, Santonocito M, Angelica R, Cavallaro A, et al: Specific alterations of the microRNA transcriptome and global network structure in colorectal cancer after treatment with MAPK/ERK inhibitors. J Mol Med (Berl) 2012, 90(12):1421-1438.

7. Ragusa M, Majorana A, Statello L, Maugeri M, Salito L, Barbagallo D, Guglielmino MR, Duro LR, Angelica R, Caltabiano R, et al: Specific alterations of microRNA transcriptome and global network structure in colorectal carcinoma after cetuximab treatment. Molecular cancer therapeutics 2010, 9(12):3396-3409.

8. Biondi A, Fisichella R, Fiorica F, Malaguarnera M, Basile F: Food mutagen and gastrointestinal cancer. European review for medical and pharmacological sciences 2012, 16(9):1280-1282.

9. Uccello M, Malaguarnera G, Corriere T, Biondi A, Basile F, Malaguarnera M: Risk of hepatocellular carcinoma in workers exposed to chemicals. Hepatitis monthly 2012, 12(10 HCC):e5943.

10. Berretta M, Lleshi A, Fisichella R, Berretta S, Basile F, Li Volti G, Bolognese A, Biondi A, De Paoli P, Tirelli U, et al: The role of nutrition in the development of esophageal cancer: what do we know? Front Biosci (Elite Ed) 2012, 4:351-357.

11. Colditz GA, Wolin KY, Gehlert S: Applying what we know to accelerate cancer prevention. Science translational medicine 2012, 4(127), 127rv124.

12. Vucenik I, Stains JP: Obesity and cancer risk: evidence, mechanisms, and recommendations. Annals of the New York Academy of Sciences 2012, 1271:37-43.

13. Keys A, Menotti A, Karvonen MJ, Aravanis C, Blackburn H, Buzina R, Djordjevic BS, Dontas AS, Fidanza F, Keys MH, et al: The diet and 15-year death rate in the seven countries study. American journal of epidemiology 1986, 124(6):903-915

14. Pauwels EK: The protective effect of the Mediterranean diet: focus on cancer and cardiovascular risk. Medical principles and practice 2011, 20(2):103-11.

15. Moreno LA, Sarria A, Popkin BM: The nutrition transition in Spain: a European Mediterranean country. European journal of clinical nutrition 2002, 56(10):992-1003.

16. Sofi F, Abbate R, Gensini GF, Casini A: Accruing evidence on benefits of adherence to the Mediterranean diet on health: an updated systematic review and meta-analysis. The American journal of clinical nutrition 2010, 92(5):1189-1196.

17. Couto E, Boffetta P, Lagiou P, Ferrari P, Buckland G, Overvad K, Dahm CC, Tjonneland A, Olsen A, Clavel-Chapelon F, et al: Mediterranean dietary pattern and cancer risk in the EPIC cohort. British journal of cancer 2011, 104(9):1493-1499.

18. Agnoli C, Grioni S, Sieri S, Palli D, Masala G, Sacerdote C, Vineis P, Tumino R, Giurdanella MC, Pala V, et al: Italian Mediterranean Index and risk of colorectal cancer in the Italian section of the EPIC cohort. International journal of cancer Journal international du cancer 2013, 132(6):1404-1411.

19. Reedy J, Mitrou PN, Krebs-Smith SM, Wirfalt E, Flood A, Kipnis V, Leitzmann M, Mouw T, Hollenbeck A, Schatzkin A, et al: Index-based dietary patterns and risk of colorectal cancer: the NIH-AARP Diet and Health Study. American journal of epidemiology 2008, 168(1):38-48.

20. Dixon LB, Subar AF, Peters U, Weissfeld JL, Bresalier RS, Risch A, Schatzkin A Hayes RB: Adherence to the USDA Food Guide, DASH Eating Plan, and Mediterranean dietary pattern reduces risk of colorectal adenoma. The Journal of nutrition 2007, 137(11):2443-2450.

21. Fung $T$, Hu FB, Wu K, Chiuve SE, Fuchs CS, Giovannucci E: The Mediterranean and Dietary Approaches to Stop Hypertension (DASH) diets and colorectal cancer. The American journal of clinical nutrition 2010 92(6):1429-1435.

22. Buckland G, Travier N, Cottet V, Gonzalez CA, Lujan-Barroso L, Agudo A, Trichopoulou A, Lagiou P, Trichopoulos D, Peeters PH, et al: Adherence to the mediterranean diet and risk of breast cancer in the European prospective investigation into cancer and nutrition cohort study. International journal of cancer Journal international du cancer 2013, 132(12):2918-2927.

23. Cade JE, Taylor EF, Burley VJ, Greenwood DC: Does the Mediterranean dietary pattern or the Healthy Diet Index influence the risk of breast cancer in a large British cohort of women? European journal of clinical nutrition 2011, 65(8):920-928.

24. Trichopoulou A, Bamia C, Lagiou P, Trichopoulos D: Conformity to traditional Mediterranean diet and breast cancer risk in the Greek EPIC (European Prospective Investigation into Cancer and Nutrition) cohort. The American journal of clinical nutrition 2010, 92(3):620-625.

25. Amato B, Rispoli C, lannone L, Testa S, Compagna R, Rocco N: Surgical margins of resection for breast cancer: Current evidence. Minerva Chirurgica 2012, 67(5):445-452.

26. Fung $T$, Hu FB, McCullough ML, Newby PK, Willett WC, Holmes MD: Diet quality is associated with the risk of estrogen receptor-negative breast 
cancer in postmenopausal women. The Journal of nutrition 2006, 136(2):466-472.

27. Cottet V, Touvier M, Fournier A, Touillaud MS, Lafay L, Clavel-Chapelon F, Boutron-Ruault MC: Postmenopausal breast cancer risk and dietary patterns in the E3N-EPIC prospective cohort study. American journal of epidemiology 2009, 170(10):1257-1267.

28. Buckland G, Agudo A, Lujan L, Jakszyn P, Bueno-de-Mesquita HB, Palli D, Boeing $H$, Carneiro F, Krogh V, Sacerdote C, et al: Adherence to a Mediterranean diet and risk of gastric adenocarcinoma within the European Prospective Investigation into Cancer and Nutrition (EPIC) cohort study. The American journal of clinical nutrition 2010, 91(2):381-390.

29. Bosire C, Stampfer MJ, Subar AF, Park Y, Kirkpatrick SI, Chiuve SE, Hollenbeck AR, Reedy J: Index-based dietary patterns and the risk of prostate cancer in the NIH-AARP diet and health study. American journal of epidemiology 2013, 177(6):504-513.

30. Dalvi TB, Canchola AJ, Horn-Ross PL: Dietary patterns, Mediterranean diet, and endometrial cancer risk. Cancer causes \& control : CCC 2007, 18(9):957-966.

31. Demetriou CA, Hadjisavvas A, Loizidou MA, Loucaides G, Neophytou I, Sieri S, Kakouri E, Middleton N, Vineis P, Kyriacou K: The mediterranean dietary pattern and breast cancer risk in Greek-Cypriot women: a casecontrol study. BMC cancer 2012, 12:113.

32. Kontou N, Psaltopoulou T, Soupos N, Polychronopoulos E, Xinopoulos D, Linos A, Panagiotakos DB: The mediating effect of Mediterranean diet on the relation between smoking and colorectal cancer: a case-control study. European journal of public health 2012.

33. Kontou N, Psaltopoulou T, Soupos N, Polychronopoulos E, Xinopoulos D, Linos A, Panagiotakos D: Alcohol consumption and colorectal cancer in a Mediterranean population: a case-control study. Diseases of the colon and rectum 2012, 55(6):703-710.

34. Murtaugh MA, Sweeney C, Giuliano AR, Herrick JS, Hines L, Byers T, Baumgartner KB, Slattery ML: Diet patterns and breast cancer risk in Hispanic and non-Hispanic white women: the Four-Corners Breast Cancer Study. The American journal of clinical nutrition 2008, 87(4):978-984.

35. Samoli E, Lagiou A, Nikolopoulos E, Lagogiannis G, Barbouni A, Lefantzis D, Trichopoulos D, Brennan P, Lagiou P: Mediterranean diet and upper aerodigestive tract cancer: the Greek segment of the Alcohol-Related Cancers and Genetic Susceptibility in Europe study. The British journal of nutrition 2010, 104(9):1369-1374.

36. Bosetti C, Gallus S, Trichopoulou A, Talamini R, Franceschi S, Negri E, La Vecchia C: Influence of the Mediterranean diet on the risk of cancers of the upper aerodigestive tract. Cancer epidemiology, biomarkers \& prevention : a publication of the American Association for Cancer Research, cosponsored by the American Society of Preventive Oncology 2003, 12(10):1091-1094.

37. La Vecchia C: Association between Mediterranean dietary patterns and cancer risk. Nutrition reviews 2009, 67(Suppl 1):S126-129.

38. Hadziabdic MO, Bozikov V, Pavic E, Romic Z: The antioxidative protecting role of the Mediterranean diet. Collegium antropologicum 2012, 36(4):1427-1434

39. Collins AR, Azqueta A, Langie SA: Effects of micronutrients on DNA repair. European journal of nutrition 2012, 51(3):261-279.

40. Grosso G, Bei R, Mistretta A, Marventano S, Calabrese G, Masuelli L, Giganti MG, Modesti A, Galvano F, Gazzolo D: Effects of Vitamin C on health: a review of evidence. Frontiers in bioscience 2013, 18:1017-29.

41. Latte KP, Appel KE, Lampen A: Health benefits and possible risks of broccoli - an overview. Food and chemical toxicology : an international journal published for the British Industrial Biological Research Association 2011 49(12):3287-3309.

42. Steinkellner H, Rabot S, Freywald C, Nobis E, Scharf G, Chabicovsky M, Knasmuller S, Kassie F: Effects of cruciferous vegetables and their constituents on drug metabolizing enzymes involved in the bioactivation of DNA-reactive dietary carcinogens. Mutation research 2001, 480-481, 285-297.

43. Nguyen HH, Aronchik I, Brar GA, Nguyen DH, Bjeldanes LF, Firestone GL: The dietary phytochemical indole-3-carbinol is a natural elastase enzymatic inhibitor that disrupts cyclin E protein processing. Proceedings of the National Academy of Sciences of the United States of America 2008, 105(50):19750-19755.

44. Aronchik I, Bjeldanes LF, Firestone GL: Direct inhibition of elastase activity by indole-3-carbinol triggers a CD40-TRAF regulatory cascade that disrupts NF-kappaB transcriptional activity in human breast cancer cells. Cancer research 2010, 70(12):4961-4971.

45. Grosso G, Galvano F, Mistretta A, Marventano S, Nolfo F, Calabrese G, Buscemi S, Drago F, Veronesi U, Scuderi A: Red orange: experimental models and epidemiological evidence of its benefits on human health. Oxidative medicine and cellular longevity 2013, 2013:157240.

46. Vitale DC, Piazza C, Melilli B, Drago F, Salomone S: Isoflavones: estrogenic activity, biological effect and bioavailability. European journal of drug metabolism and pharmacokinetics 2013, 38(1):15-25.

47. Kocic B, Filipovic S, Nikolic M, Petrovic B: Effects of anthocyanins and anthocyanin-rich extracts on the risk for cancers of the gastrointestinal tract. Journal of BUON : official journal of the Balkan Union of Oncology 2011, 16(4):602-608.

48. Galvano F, Frigiola A, Gazzolo D, Biondi A, Malaguarnera M, Li Volti G: Endothelial protective effects of anthocyanins: the underestimated role of their metabolites. Annals of nutrition \& metabolism 2009, 54(2):158-159.

49. Masella R, Santangelo C, D'Archivio M, Li Volti G, Giovannini C, Galvano F: Protocatechuic acid and human disease prevention: biological activities and molecular mechanisms. Current medicinal chemistry 2012, 19(18):2901-2917.

50. Kamaraj S, Anandakumar P, Jagan S, Ramakrishnan G, Devaki T: Modulatory effect of hesperidin on benzo(a)pyrene induced experimental lung carcinogenesis with reference to COX-2, MMP-2 and MMP-9. European journal of pharmacology 2010, 649(1):320-327.

51. Balakrishnan A, Menon VP: Effect of hesperidin on matrix metalloproteinases and antioxidant status during nicotine-induced toxicity. Toxicology 2007, 238(23):90-98.

52. Yeh MH, Kao ST, Hung CM, Liu CJ, Lee KH, Yeh CC: Hesperidin inhibited acetaldehyde-induced matrix metalloproteinase- 9 gene expression in human hepatocellular carcinoma cells. Toxicology letters 2009, 184(3):204-210.

53. Sivagami G, Vinothkumar R, Preethy CP, Riyasdeen A, Akbarsha MA, Menon VP, Nalini N: Role of hesperetin (a natural flavonoid) and its analogue on apoptosis in HT-29 human colon adenocarcinoma cell linea comparative study. Food and chemical toxicology : an international journal published for the British Industrial Biological Research Association 2012, 50(34):660-671.

54. Ghorbani A, Nazari M, Jeddi-Tehrani M, Zand H: The citrus flavonoid hesperidin induces p53 and inhibits NF-kappaB activation in order to trigger apoptosis in NALM-6 cells: involvement of PPARgammadependent mechanism. European journal of nutrition 2012, 51(1):39-46.

55. Leonardi T, Vanamala J, Taddeo SS, Davidson LA, Murphy ME, Patil BS, Wang N, Carroll RJ, Chapkin RS, Lupton JR, et al: Apigenin and naringenin suppress colon carcinogenesis through the aberrant crypt stage in azoxymethane-treated rats. Exp Biol Med (Maywood) 2010, 235(6):710-717.

56. Park HJ, Kim MJ, Ha E, Chung JH: Apoptotic effect of hesperidin through caspase3 activation in human colon cancer cells, SNU-C4. Phytomedicine : international journal of phytotherapy and phytopharmacology 2008, 15(12):147-151.

57. Gomez-Romero M, Arraez-Roman D, Segura-Carretero A, FernandezGutierrez A: Analytical determination of antioxidants in tomato: typical components of the Mediterranean diet. Journal of separation science 2007, 30(4):452-461.

58. Stahl W, Heinrich U, Aust O, Tronnier H, Sies H: Lycopene-rich products and dietary photoprotection. Photochemical \& photobiological sciences: Official journal of the European Photochemistry Association and the European Society for Photobiology 2006, 5(2):238-242.

59. Stahl W, Heinrich U, Wiseman S, Eichler O, Sies H, Tronnier H: Dietary tomato paste protects against ultraviolet light-induced erythema in humans. The Journal of nutrition 2001, 131(5):1449-1451.

60. Unlu NZ, Bohn T, Francis DM, Nagaraja HN, Clinton SK, Schwartz SJ: Lycopene from heat-induced cis-isomer-rich tomato sauce is more bioavailable than from all-trans-rich tomato sauce in human subjects. The British journal of nutrition 2007, 98(1):140-146.

61. Shi J, Le Maguer M: Lycopene in tomatoes: chemical and physical properties affected by food processing. Critical reviews in biotechnology 2000, 20(4):293-334.

62. Basu A, Imrhan V: Tomatoes versus lycopene in oxidative stress and carcinogenesis: conclusions from clinical trials. European journal of clinical nutrition 2007, 61(3):295-303. 
63. Rizwan M, Rodriguez-Blanco I, Harbottle A, Birch-Machin MA, Watson RE, Rhodes LE: Tomato paste rich in lycopene protects against cutaneous photodamage in humans in vivo: a randomized controlled trial. The British journal of dermatology 2011, 164(1):154-162.

64. Aust O, Stahl W, Sies H, Tronnier H, Heinrich U: Supplementation with tomato-based products increases lycopene, phytofluene, and phytoene levels in human serum and protects against UV-light-induced erythema. International journal for vitamin and nutrition research Internationale Zeitschrift fur Vitamin- und Ernahrungsforschung Journal international de vitaminologie et de nutrition 2005, 75(1):54-60.

65. Jamshidzadeh A, Baghban M, Azarpira N, Mohammadi Bardbori A Niknahad $\mathrm{H}$ : Effects of tomato extract on oxidative stress induced toxicity in different organs of rats. Food and chemical toxicology : an international journal published for the British Industrial Biological Research Association 2008, 46(12):3612-3615.

66. Talvas J, Caris-Veyrat C, Guy L, Rambeau M, Lyan B, Minet-Quinard R, Lobaccaro JM, Vasson MP, George S, Mazur A, et al: Differential effects of lycopene consumed in tomato paste and lycopene in the form of a purified extract on target genes of cancer prostatic cells. The American journal of clinical nutrition 2010, 91(6):1716-1724.

67. Gonzali S, Mazzucato A, Perata P: Purple as a tomato: towards high anthocyanin tomatoes. Trends in plant science 2009, 14(5):237-241.

68. Chan DS, Lau R, Aune D, Vieira R, Greenwood DC, Kampman E, Norat T: Red and processed meat and colorectal cancer incidence: meta-analysis of prospective studies. PloS one 2011, 6(6):e20456.

69. Santarelli RL, Pierre F, Corpet DE: Processed meat and colorectal cancer: a review of epidemiologic and experimental evidence. Nutrition and cancer 2008, 60(2):131-144.

70. Alexander DD, Morimoto LM, Mink PJ, Cushing CA: A review and metaanalysis of red and processed meat consumption and breast cancer. Nutrition research reviews 2010, 23(2):349-365.

71. Taylor VH, Misra M, Mukherjee SD: Is red meat intake a risk factor for breast cancer among premenopausal women? Breast cancer research and treatment 2009, 117(1):1-8.

72. Salehi M, Moradi-Lakeh M, Salehi MH, Nojomi M, Kolahdooz F: Meat, fish, and esophageal cancer risk: a systematic review and dose-response meta-analysis. Nutrition reviews 2013, 71(5):257-267.

73. Choi $Y$, Song S, Song Y, Lee JE: Consumption of red and processed meat and esophageal cancer risk: meta-analysis. World journal of gastroenterology: WJG 2013, 19(7):1020-1029.

74. Yang WS, Wong MY, Vogtmann E, Tang RQ, Xie L, Yang YS, Wu QJ, Zhang W, Xiang YB: Meat consumption and risk of lung cancer: evidence from observational studies. Annals of oncology : official journal of the European Society for Medical Oncology / ESMO 2012, 23(12):3163-3170.

75. Larsson SC, Wolk A: Red and processed meat consumption and risk of pancreatic cancer: meta-analysis of prospective studies. British journal of cancer 2012, 106(3):603-607.

76. Wang $\mathrm{C}$, Jiang $\mathrm{H}$ : Meat intake and risk of bladder cancer: a meta-analysis. Med Oncol 2012, 29(2):848-855.

77. Rispoli C, Rocco N, lannone L, Amato B: Developing guidelines in geriatric surgery:role of the grade system. BMC Geriatrics 2009, 9(SUPPL.1):A99.

78. Alexander DD, Cushing CA: Quantitative assessment of red meat or processed meat consumption and kidney cancer. Cancer detection and prevention 2009, 32(56):340-351.

79. Wallin A, Orsini N, Wolk A: Red and processed meat consumption and risk of ovarian cancer: a dose-response meta-analysis of prospective studies. British journal of cancer 2011, 104(7):1196-1201.

80. Chatenoud L, Tavani A, La Vecchia C, Jacobs DR, Negri E, Levi F, Franceschi S: Whole grain food intake and cancer risk. International journal of cancer Journal international du cancer 1998, 77(1):24-28.

81. Chatenoud L, La Vecchia C, Franceschi S, Tavani A, Jacobs DR, Parpinel MT, Soler M, Negri E: Refined-cereal intake and risk of selected cancers in italy. The American journal of clinical nutrition 1999, 70(6):1107-1110.

82. Uchida K, Kono S, Yin G, Toyomura K, Nagano J, Mizoue T, Mibu R, Tanaka M, Kakeji $Y$, Maehara $Y$, et al: Dietary fiber, source foods and colorectal cancer risk: the Fukuoka Colorectal Cancer Study. Scandinavian journal of gastroenterology 2010, 45(10):1223-1231.

83. Dahm CC, Keogh RH, Spencer EA, Greenwood DC, Key TJ, Fentiman IS, Shipley MJ, Brunner EJ, Cade JE, Burley VJ, et al: Dietary fiber and colorectal cancer risk: a nested case-control study using food diaries. Journal of the National Cancer Institute 2010, 102(9):614-626.
84. Bosetti C, Pelucchi C, La Vecchia C: Diet and cancer in Mediterranean countries: carbohydrates and fats. Public health nutrition 2009, 12(9A):1595-1600.

85. Park $Y$, Subar AF, Hollenbeck A, Schatzkin A: Dietary fiber intake and mortality in the NIH-AARP diet and health study. Archives of internal medicine 2011, 171(12):1061-1068.

86. Pelucchi C, Talamini R, Levi F, Bosetti C, La Vecchia C, Negri E, Parpinel M, Franceschi S: Fibre intake and laryngeal cancer risk. Annals of oncology: official journal of the European Society for Medical Oncology / ESMO 2003, 14(1):162-167.

87. Soler M, Bosetti C, Franceschi S, Negri E, Zambon P, Talamini R, Conti E, La Vecchia C: Fiber intake and the risk of oral, pharyngeal and esophageal cancer. International journal of cancer Journal international du cancer 2001, 91(3):283-287.

88. Lim CC, Ferguson LR, Tannock GW: Dietary fibres as "prebiotics": implications for colorectal cancer. Molecular nutrition \& food research 2005, 49(6):609-619.

89. Uccello M, Malaguarnera G, Basile F, D'Agata V, Malaguarnera M, Bertino G, Vacante M, Drago F, Biondi A: Potential role of probiotics on colorectal cancer prevention. BMC surgery 2012, 12(Suppl 1):S35.

90. Fung KY, Cosgrove L, Lockett T, Head R, Topping DL: A review of the potential mechanisms for the lowering of colorectal oncogenesis by butyrate. The British journal of nutrition 2012, 108(5):820-831.

91. Biddinger SB, Ludwig DS: The insulin-like growth factor axis: a potential link between glycemic index and cancer. The American journal of clinical nutrition 2005, 82(2):277-278.

92. Renehan AG, Frystyk J, Flyvbjerg A: Obesity and cancer risk: the role of the insulin-IGF axis. Trends in endocrinology and metabolism: TEM 2006, 17(8):328-336.

93. Choi Y, Giovannucci E, Lee JE: Glycaemic index and glycaemic load in relation to risk of diabetes-related cancers: a meta-analysis. The British journal of nutrition 2012, 108(11):1934-1947.

94. Mulholland HG, Murray LJ, Cardwell CR, Cantwell MM: Glycemic index, glycemic load, and risk of digestive tract neoplasms: a systematic review and meta-analysis. The American journal of clinical nutrition 2009, 89(2):568-576.

95. Price RK, Keaveney EM, Hamill LL, Wallace JM, Ward M, Ueland PM, McNulty H, Strain JJ, Parker MJ, Welch RW: Consumption of wheat aleurone-rich foods increases fasting plasma betaine and modestly decreases fasting homocysteine and LDL-cholesterol in adults. The Journal of nutrition 2010, 140(12):2153-2157.

96. Psaltopoulou T, Kosti RI, Haidopoulos D, Dimopoulos M, Panagiotakos DB: Olive oil intake is inversely related to cancer prevalence: a systematic review and a meta-analysis of 13,800 patients and 23,340 controls in 19 observational studies. Lipids in health and disease 2011, 10:127.

97. Perez-Jimenez F, Ros E, De L Badimon CR, Covas MI, Escrich E, Ordovas JM, Soriguer F, Abia R, de la Lastra CA, Battino M, Corella D, Chamorro-Quiros J, Delgado-Lista J, Giugliano D, Esposito K, Estruch R, Fernandez-Real JM, Gaforio JJ, La VC, Lairon D, Lopez-Segura F, Mata P, Menendez JA, Muriana FJ, Osada J, Panagiotakos DB, Paniagua JA, Perez-Martinez P, Perona J, Peinado MA, Pineda-Priego M, Poulsen HE, Quiles JL, RamirezTortosa MC, Ruano J, Serra-Majem L, Sola R, Solanas M, Solfrizzi V, TorreFornell R, Trichopoulou A, Uceda M, Villalba-Montoro JM, Villar-Ortiz JR, Visioli F, Yiannakouris N: Olive oil and health: summary of the II international conference on olive oil and health consensus report, Jaen and Cordoba (Spain) 2008. Nutrition metabolism and cardiovascular disease 2010, 20:284-294.

98. Pelucchi C, Bosetti C, Negri E, Lipworth L, La Vecchia C: Olive oil and cancer risk: an update of epidemiological findings through 2010. Current pharmaceutical design 2011, 17(8):805-812.

99. St-Laurent-Thibault C, Arseneault M, Longpre F, Ramassamy C: Tyrosol and hydroxytyrosol, two main components of olive oil, protect N2a cells against amyloid-beta-induced toxicity. Involvement of the NF-kappaB signaling. Current Alzheimer research 2011, 8(5):543-551.

100. Aluyen JK, Ton QN, Tran T, Yang AE, Gottlieb HB, Bellanger RA: Resveratrol: potential as anticancer agent. Journal of dietary supplements 2012, 9(1):45-56.

101. Bradamante $S$, Barenghi L, Villa A: Cardiovascular protective effects of resveratrol. Cardiovascular drug reviews 2004, 22(3):169-188.

102. Ulrich S, Wolter F, Stein JM: Molecular mechanisms of the chemopreventive effects of resveratrol and its analogs in carcinogenesis. Molecular nutrition \& food research 2005, 49(5):452-461. 
103. Shankar S, Singh G, Srivastava RK: Chemoprevention by resveratrol: molecular mechanisms and therapeutic potential. Frontiers in bioscience: a journal and virtual library 2007, 12:4839-4854.

104. de la Lastra CA, Villegas I: Resveratrol as an antioxidant and pro-oxidant agent: mechanisms and clinical implications. Biochemical Society transactions 2007, 35(Pt 5):1156-1160.

105. Chao C, Li Q, Zhang F, White E: Alcohol consumption and risk of lung cancer in the VITamins And Lifestyle Study. Nutrition and cancer 2011, 63(6):880-888.

106. Chao C, Haque R, Caan BJ, Poon KY, Tseng HF, Quinn VP: Red wine consumption not associated with reduced risk of colorectal cancer. Nutrition and cancer 2010, 62(6):849-855.

107. Sutcliffe S, Giovannucci E, Leitzmann MF, Rimm EB, Stampfer MJ, Willett WC, Platz EA: A prospective cohort study of red wine consumption and risk of prostate cancer. International journal of cancer Journal international du cancer 2007, 120(7):1529-1535.

doi:10.1186/1471-2482-13-S2-S14

Cite this article as: Grosso et al:: Mediterranean diet and cancer: epidemiological evidence and mechanism of selected aspects. BMC Surgery 2013 13(Suppl 2):S14.

\section{Submit your next manuscript to BioMed Central} and take full advantage of:

- Convenient online submission

- Thorough peer review

- No space constraints or color figure charges

- Immediate publication on acceptance

- Inclusion in PubMed, CAS, Scopus and Google Scholar

- Research which is freely available for redistribution

Submit your manuscript at www.biomedcentral.com/submit 